\title{
O princípio da Gestão Democrática e sua aplicação no ensino público no Piauí
}

\section{The Principle of Democratic Management}

and its application in public education in Piauí

\section{El Principio de la Gestión Democrática}

y su aplicación en la enseñanza pública en el Piauí

\section{RAIMUNDA MARIA DA CUNHA RIBEIRO* \\ Universidade Estadual do Piauí, Corrente- PI, Brasil.}

\begin{abstract}
RESUMO: Este artigo tem os objetivos de compreender o debate sobre gestão democrática do ensino público; fazer um levantamento das leis de criação dos sistemas municipais de ensino no Piauí para identificar as orientações legais acerca do princípio da gestão democrática. A metodologia foi quali-quantitativa, a técnica foi a análise documental de 97 leis.
\end{abstract}

Palavras-chave: Gestão democrática. Ensino público. Sistemas municipais.

\begin{abstract}
This article aims to understand the debate on democratic management of public education; make a survey of the stablishing laws of municipal education systems in Piauí to identify the legal guidelines on the principle of democratic management. The methodology was qualitative-quantitative, the technique was the documentary analysis of 97 laws.
\end{abstract}

Keywords: Democratic management. Public education. Municipal systems.

* Possui mestrado em Educação pela Universidade Católica de Brasília, doutorado em Ciências da Educação pela Universidade Tecnológica Intercontinental e doutorado em Educação pela Pontifícia Universidade Católica do Rio Grande do Sul. Atualmente é professora do curso de Pedagogia na Universidade Estadual do Piauí, no campus de Corrente. E-mail: <raicribeiro@hotmail.com>. 
RESUMEN: Este artículo tiene los objetivos de comprender el debate sobre gestión democrática de la enseñanza pública y hacer una recolección de las leyes de creación de los sistemas municipales de enseñanza en Piauí para identificar las orientaciones legales sobre el principio de la gestión democrática. La metodología fue cualitativa y cuantitativa, la técnica fue el análisis documental de 97 leyes.

Palabras clave: Gestión democrática. Enseñanza pública. Sistemas municipales.

\section{Introdução}

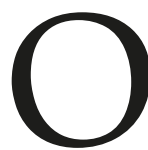

princípio da gestão democrática, definido na Constituição Federal de 1988, reforça o debate sobre a implementação da democracia na escola pública. Uma forma de inaugurar este expediente é proporcionar ao município, enquanto ente federado, condições de se tornar sistema autônomo de ensino. A democracia e a descentralização são componentes condicionantes frente à legitimação do município como ente autônomo, legitimamente referenciado pela Constituição. O município passa, então, a contar com a possibilidade de organizar sua política educacional, considerando as peculiaridades locais. Sob esta perspectiva nos orientamos, para realizar este estudo a partir da seguinte questão: o Piauí está colocado numa posição coadjuvante ou protagonista em relação à institucionalização dos sistemas municipais de ensino, de forma a cumprir o preceito constitucional de implementar a gestão democrática do ensino público?

Para responder a esta questão, nos pautamos pelos seguintes objetivos: compreender o debate sobre gestão democrática do ensino público, adotando como principal fundamento a Constituição Federal; fazer um levantamento das leis de criação dos sistemas municipais de ensino no Piauí, para identificar as orientações legais acerca do princípio da gestão democrática.

A pesquisa adotou as seguintes etapas: i) estudo, sob a perspectiva teórica acerca do princípio constitucional da gestão democrática do ensino público e a figura do município no processo de organização de sua gestão educacional; ii) levantamento das leis de criação dos sistemas municipais de ensino no estado do Piaúí iii) identificação, nas leis, do dispositivo gestão democrática e os respectivos princípios orientadores da organização da educação municipal.

Trata-se de uma pesquisa de abordagem tanto qualitativa quanto quantitativa, cuja técnica de coleta de dados foi a análise documental de um conjunto de 97 Leis. Por uma questão de ordem didática, os dados estão organizados por mesorregiões, tendo em vista a divisão geográfica adotada pelo IBGE: Norte, Centro-Norte, Sudeste e Sudoeste. 
O princípio da gestão democrática e a institucionalização dos sistemas municipais de ensino são as principais categorias de análise à luz da legislação municipal.

A finalidade da utilização das duas abordagens de pesquisa (qualitativa e quantitativa) foi no sentido de demonstrar os resultados de forma a prevalecer o equilíbrio entre a objetividade dos dados estatísticos apresentados em mapa e tabelas e a subjetividade apontada para os conteúdos analisados na legislação. A análise do conteúdo foi feita com base nos princípios orientados por Bardin (2010).

O artigo está dividido em duas seções: a primeira traz à discussão categorias como: gestão democrática, participação, disputa de poder, autonomia, regime de colaboração, em atendimento ao primeiro objetivo; a segunda seção apresenta os dados referentes à institucionalização dos municípios no Piauí, contemplando o segundo objetivo, a partir das seguintes categorias de análise: frequência dos municípios com e sem sistema de ensino; frequência do dispositivo gestão democrática no corpus das leis; frequência dos princípios da gestão democrática presentes no conjunto da legislação.

\section{A disciplina da gestão democrática nos municípios}

Recobrando os passos da história da educação brasileira, vemos que a criação de sistemas municipais de ensino nasce mesmo antes da Constituição de 1988. Sarmento (2005) nos dá indicativos que esta ideia estava presente já na segunda metade do século passado, mesmo nos governos militares, de forma que reascendia a perspectiva de valorização do nível local, a descentralização e a distribuição de competências entre os níveis municipal, estadual e federal.

A Carta amplia os direitos existentes, determina outros e dispõe, pela primeira vez, da organização dos sistemas municipais de ensino. Em atendimento ao dispositivo constitucional, a Lei de Diretrizes e Bases n. 9394/96 estabelece a mesma orientação no artigo 11 de seu texto. Neste entendimento, os municípios passam a criar seus próprios sistemas de ensino, com autonomia relativa na formulação de políticas educacionais (SOUZA; FARIA, 2004). A Carta, ao conferir ao município autonomia político-administrativa, insere-o no processo de descentralização e redistribuição de poder, de competências, de recursos e de encargos originários dos organismos centrais (PEREIRA, 2014), colocando o município como ente federativo a atuar em regime de colaboração com o estado e a União (SARMENTO, 2005).

Sarmento (2005), em sua análise sobre a institucionalização dos sistemas municipais de ensino, nos remete às seguintes reflexões, de forma a evidenciar os dois lados desse processo: i) o município tem sido apontado como um campo potencializador de experiências democráticas, pela proximidade do governo local com os sujeitos; ii) a adoção de políticas neoliberais estimulou o repasse de responsabilidades para os municípios sem considerar suas reais condições de administração. A institucionalização, portanto, imprime a autonomia, de forma a 
requerer que sejam definidas as competências e as responsabilidades municipais na oferta e na gestão da educação (PANIS; NARDI, 2014).

Ao tempo em que inserimos o conceito de autonomia no cenário desta discussão, consideramos oportuno discutir sobre o regime de colaboração entre os entes federados, incluindo o município, em conformidade com o art. 211 da CF/88: "A União, os estados, o Distrito Federal e os municípios organizarão em regime de colaboração seus sistemas de ensino", reforçado no Art. 8aㅡ da LDB de 1996, indicando à União a incumbência de coordenar a política nacional de educação, articulando os diferentes níveis e sistemas de ensino. Fica, dessa forma, a proposição das competências e das responsabilidades de cada ente certificada pela Constituição Federal.

A transferência de competências do Poder Central para os estados, o Distrito Federal e os municípios tende a nos remeter à lógica da desburocratização e da descentralização dos serviços e das políticas educacionais. Por esta razão, Sarmento (2005) nos aponta o município como um campo propício às experiências democráticas. Este feito constitucional faculta aos municípios o direito de emitir normas eestabelecer políticas, viabilizando, dessa forma, a materialização do regime de colaboração, indo além das relações hierárquicas entre as três esferas políticas de poder (SOUZA; FARIA, 2004). Neste caso, a descentralização torna-se uma importante conquista da democracia na gestão educacional, incluindo a efetiva participação social.

Vale imprimir que, por muitos anos, conforme assinalam Werle; Thum; Andrade (2009), declaramos a necessidade de espaços mais participativos na educação pública brasileira, ao tempo em que ansiamos pela possibilidade de decisões mais autônomas, articuladas às necessidades locais. Ressaltamos as palavras de Souza; Faria (2004): em que pese a importância da Constituição Federal sobre o regime de colaboração e transferência de poder para os entes federados, a definição clara sobre a competência dos municípios para a institucionalização de seus próprios sistemas de ensino decorre mais especificamente das definições previstas na LDB.

A cultura da participação nos permite conhecer espaços e mecanismos de materialização da gestão democrática do ensino público, por meio dos processos de planejamento, de implementação e de avaliação de um projeto social de educação. Ademais, é forçoso admitir que a participação não tem andado no mesmo compasso das exigências da gestão democrática e umas das razões para tal é a existência de conflitos, tensões e disputas de poder no interior dos sistemas municipais de ensino (PEREIRA, 2012). Neste entendimento também se encontram os achados de Lima (2009), ao considerar que a democracia e a democratização se inserem num espaço de disputa em que o Estado se instaura para a representação das classes sociais.

Enfim, a implantação dos sistemas municipais de ensino é uma tarefa em processo. Parte dos municípios brasileiros ainda está fora do quadro dos sistemas autônomos, mesmo com todas as orientações dos dispositivos legais, como veremos o caso do estado do Piauí, na seção seguinte. Vale considerar que a nova forma de gestão educacional nos municípios exige uma equipe, além de comprometida, tecnicamente preparada e habilitada para implementar a gestão democrática do ensino público. 
Fizemos o levantamento e a análise das leis de criação dos sistemas municipais de ensino no estado do Piauí, de forma a identificar o princípio da gestão democrática impresso nos documentos, o que nos permite inferir, em termos de institucionalização dos sistemas municipais de ensino, se o Piauí é um estado protagonista ou se seus municípios continuam a organizar a educação em conformidade com as diretrizes estabelecidas pela Secretaria Estadual de Educação (Seduc-PI).

\section{A institucionalização dos sistemas municipais de ensino}

Esta seção traz os dados referentes à pesquisa documental, cujo objeto de análise está constituído pelo conjunto das 97 leis de criação dos sistemas municipais de ensino no estado do Piauí. Propomos sua organização a partir das seguintes categorias: divisão geográfica do Piauí (mesorregiões); frequência dos municípios com sistema de ensino institucionalizado; frequência do dispositivo gestão democrática na legislação; frequência dos princípios da gestão democrática, expressos no conjunto da legislação.

Os dados estão organizados por mesorregião, conforme o Mapa 1.

Mapa 1. Mesorregiões geográficas do Piauí

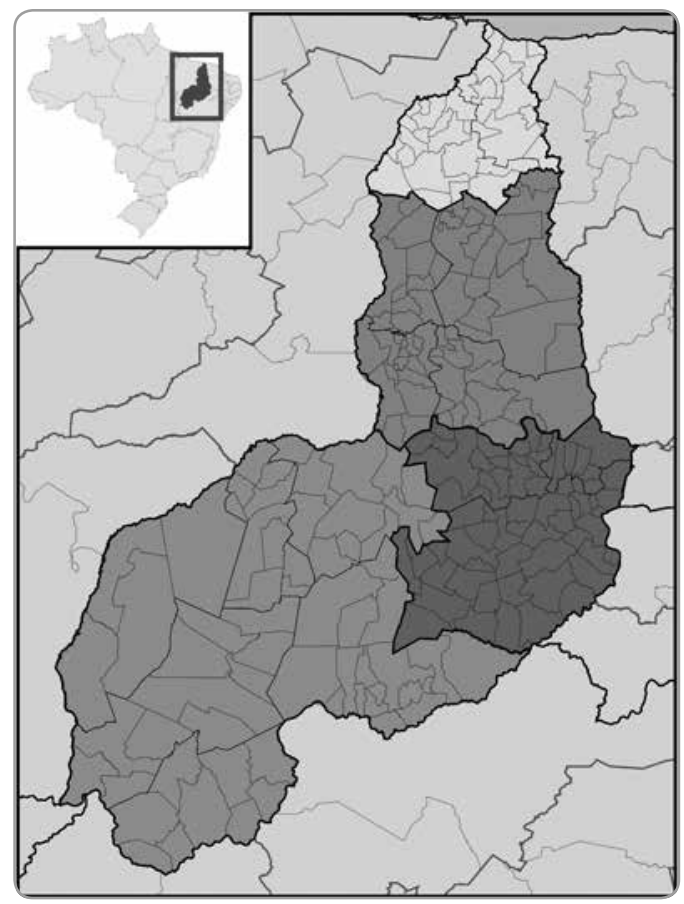

Fonte: IBGE (2011) 
O estado do Piauí está divido geograficamente em quatro mesorregiões - Norte, Centro Norte, Sudeste e Sudoeste - citadas pelo IBGE, porém, convém lembrar que não se constituem entidades políticas ou administrativas, mas sua finalidade se limita a fins estatísticos.

O Mapa 2 apresenta a frequência dos municípios piauienses com e sem sistema próprio de ensino, de forma que podemos identificar que o maior número está relacionado aos municípios sem sistema de ensino, vinculados à Secretaria Estadual de Educação e Cultura (Seduc-Pi). Embora os dados sejam de 2016, não há mudanças significativas no cenário, como veremos adiante.

\section{Mapa 2. Municípios piauienses com e sem sistema próprio de ensino público}

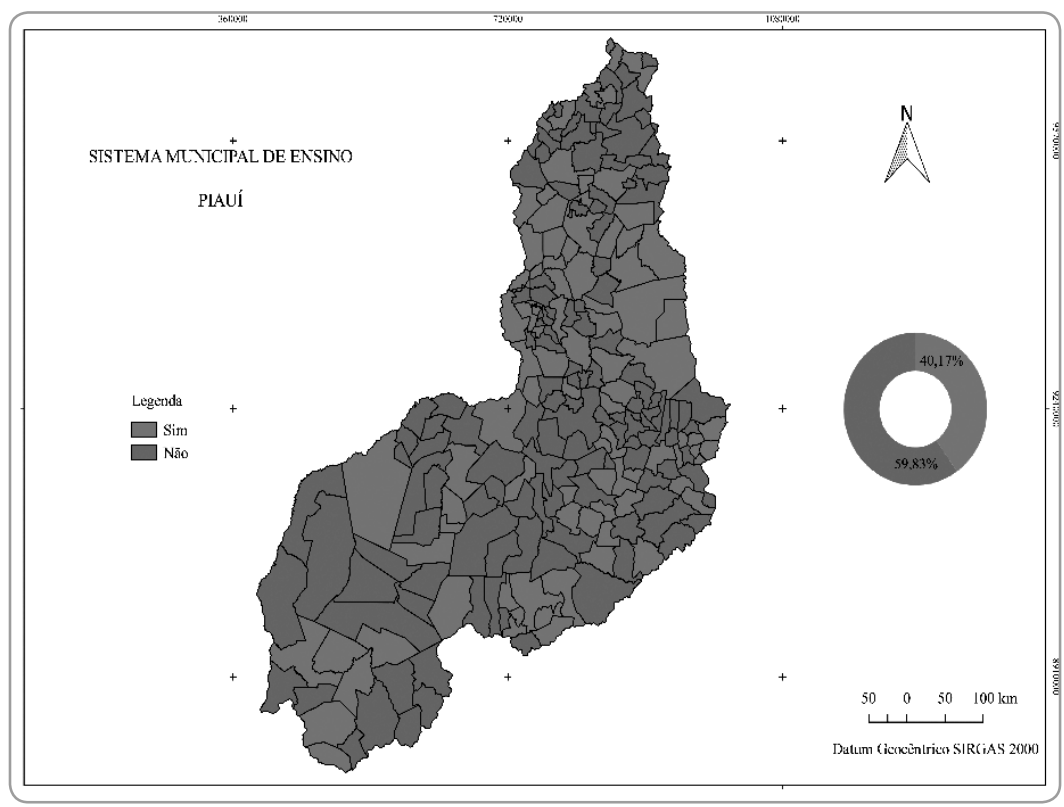

Fonte: Rede Mapa/Coordenação do Piauí (2016).

As orientações para a institucionalização dos sistemas municipais de ensino no Piauí são emitidas pelo Conselho Estadual de Educação, de forma que a organização da educação deva atender ao disposto na legislação: i) Art. 211 da CF/88; ii) Art. 8o e Art. 18 da LDB/96; iii) Art. 8o da Lei Estadual n. 5.101/1999; iv) Parecer CEE/PI n. 054/2004.

Em atendimento à CF e à LDB, a Lei Estadual n. 5.101/1999, por seu turno, expressa que os municípios, ao organizarem seu sistema de ensino, devem constituir seus órgãos executivo e normativo, comunicando, na sequência, ao Conselho Estadual de Educação. O município, ao tomar a decisão de institucionalizar seu sistema de ensino, segue as recomendações impressas no Parecer Ceep/2004. 
As orientações do Parecer Ceep/2004 para a implantação do sistema seguem nesta ordem: i) edição de lei específica, aprovada na Câmara Municipal, criando o sistema e seus órgãos constitutivos: Executivo (Secretaria Municipal de Educação), Normativo e Consultivo (Conselho Municipal de Educação); ii) instalação de órgão encarregado do controle ou autenticação de documentos escolares expedidos pela rede de escolas do sistema: iii) nomeação dos membros do Conselho Municipal de Educação, de acordo com o disposto na Lei de criação do sistema já aprovada; iv) instalação do Conselho Municipal de Educação e aprovação de seu regimento, por Lei ou sancionado através de Decreto do prefeito; v) comunicação ao Conselho Estadual de Educação o início da vigência do sistema, através de processo (Lei de criação do sistema, do conselho e o regimento do conselho); vi) emissão de Portaria pelo Conselho Estadual de Educação, informando a criação do sistema; vii) comunicação à Seduc da criação do novo sistema.

As tabelas 1, 2, 3 e 4 apresentam os dados advindos da legislação municipal, objeto de análise nesta investigação, organizados por mesorregiões e assim categorizados: frequência dos municípios com e sem sistema de ensino; frequência do dispositivo gestão democrática na legislação; frequência dos princípios da gestão democrática, expressos nas leis, restritos ao Art. 14 da LDB/96; frequência dos princípios da gestão democrática, expressos nas leis, além dos expressos no Art. 14 da LDB/96.

\section{Tabela 1. Frequência dos municípios piauienses com e sem sistema próprio de ensino por mesorregião}

\begin{tabular}{|c|c|c|c|c|c|c|c|c|}
\hline \multirow{4}{*}{ 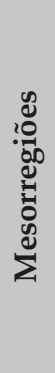 } & \multicolumn{2}{|c|}{$\begin{array}{l}\text { Norte Piauiense } \\
\text { (32 municípios) }\end{array}$} & \multicolumn{2}{|c|}{$\begin{array}{l}\text { Centro Norte } \\
\text { Piauiense } \\
\text { (64 municípios) }\end{array}$} & \multicolumn{2}{|c|}{$\begin{array}{c}\text { Sudeste } \\
\text { Piauiense } \\
\text { (66 municípios) }\end{array}$} & \multicolumn{2}{|c|}{$\begin{array}{c}\text { Sudoeste } \\
\text { Piauiense } \\
\text { (62 municípios) }\end{array}$} \\
\hline & $\begin{array}{l}\text { Com } \\
\text { SME }\end{array}$ & $\begin{array}{l}\text { Sem } \\
\text { SME }\end{array}$ & $\begin{array}{l}\text { Com } \\
\text { SME }\end{array}$ & $\begin{array}{l}\text { Sem } \\
\text { SME }\end{array}$ & $\begin{array}{l}\text { Com } \\
\text { SME }\end{array}$ & $\begin{array}{l}\text { Sem } \\
\text { SME }\end{array}$ & $\begin{array}{l}\text { Com } \\
\text { SME }\end{array}$ & $\begin{array}{l}\text { Sem } \\
\text { SME }\end{array}$ \\
\hline & $(11 \mathrm{M})$ & $(21 \mathrm{M})$ & $(34 \mathrm{M})$ & $(30 \mathrm{M})$ & $(28 \mathrm{M})$ & $(39 \mathrm{M})$ & $(24 \mathrm{M})$ & $(38 \mathrm{M})$ \\
\hline & $34,37 \%$ & $65.63 \%$ & $53,1 \%$ & $46.9 \%$ & $42,42 \%$ & $57,58 \%$ & $38,7 \%$ & $61,3 \%$ \\
\hline
\end{tabular}

Fonte: Rede Mapa/Coordenação no estado do Piauí (2018)

Os dados levantados nos permitem chegar a algumas considerações: há mais municípios vinculados à Seduc/PI no estado, que municípios com sistemas próprios de ensino, com exceção da mesorregião Centro Norte, na qual 53,1\% dos municípios têm sistemas de ensino institucionalizados; os municípios sem sistema próprio de ensino, integrados à Seduc-PI, não têm Conselho Municipal de Educação, logo, são subordinados às deliberações do Conselho Estadual de Educação do Piauí.

O estado do Piauí tem atualmente 97 municípios com sistemas de ensino, representando 43,3\% de um total de 224 municípios. Em 30 anos de Constituição Federal, 
na qual está fundamentado e garantido o princípio da gestão democrática do ensino público, municípios piauienses não conseguiram atingir a escala de 50\% de sistemas de ensino autônomos. Importa imprimir que 56,7\% destes dependem das deliberações do Sistema Estadual de Ensino: sem autonomia, educação centralizada nas decisões da esfera estadual; ausência de participação da comunidade local nos espaços e mecanismos da gestão do ensino público. Consideramos oportuno pontuar aqui municípios sem sistemas de ensino distantes de Teresina em, aproximadamente, $900 \mathrm{Km}$ (ex. Parnaguá, Curimatá, Avelino Lopes, Sebastião Barros, Barreiras, São Gonçalo do Gurgueia, Morro Cabeça no Tempo), o que pode dificultar, inclusive, a comunicação entre o município e a Seduc-PI (sediada na Capital), provocando, por vezes, o distanciamento institucional.

A Constituição de 1988 inaugura uma nova era, a era da democracia, da garantia de diretos sociais, de possibilidades de participação, da autonomia e da descentralização. É nesse cenário que é permitido ao município criar suas próprias regras de gestão democrática da educação, consagrando o poder local como espaço de decisões, com autonomia para gerir uma rede de escolas mantidas e administradas pelo poder municipal (PEREIRA, 2014). O princípio constitucional de democracia na gestão educacional, em específico, no âmbito municipal, conforme dados do estudo em questão, não tem encontrado espaço para se materializar de forma plena. Seria uma resistência dos municípios em se comprometer com a implantação de sua própria gestão educacional, autônoma, democrática e descentralizada e se assumirem como protagonistas neste processo? Sem uma resposta totalizadora para esta questão, apresentamos outros dados que nos permitem a compreensão do cenário atual do Piauí.

Os dados da tabela a seguir nos permitem refletir sobre um aspecto importante nesta discussão: parte dos municípios cria o sistema de ensino, mas não diz legalmente quais os princípios que direcionam a gestão da educação municipal. Dos 97 municípios com sistema de ensino, 40 (41,2\%) não apontam na Lei de institucionalização qualquer dispositivo sobre gestão democrática do ensino público.

\section{Tabela 2. Frequência do dispositivo gestão democrática na legislação}

\begin{tabular}{|c|c|c|c|c|c|c|c|c|}
\hline \multirow{5}{*}{ 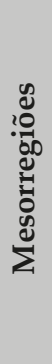 } & \multicolumn{2}{|c|}{ Norte Piauiense } & \multicolumn{2}{|c|}{$\begin{array}{l}\text { Centro Norte } \\
\text { Piauiense }\end{array}$} & \multicolumn{2}{|c|}{ Sudeste Piauiense } & \multicolumn{2}{|c|}{$\begin{array}{l}\text { Sudoeste } \\
\text { Piauiense }\end{array}$} \\
\hline & \multicolumn{2}{|c|}{11 Leis } & \multicolumn{2}{|c|}{34 Leis } & \multicolumn{2}{|c|}{28 Leis } & \multicolumn{2}{|c|}{24 Leis } \\
\hline & $\begin{array}{c}\text { Com } \\
\text { dispositivo }\end{array}$ & $\begin{array}{c}\text { Sem } \\
\text { dispositivo }\end{array}$ & $\begin{array}{c}\text { Com } \\
\text { dispositivo }\end{array}$ & $\begin{array}{c}\text { Sem } \\
\text { Dispositivo }\end{array}$ & $\begin{array}{c}\text { Com } \\
\text { dispositivo }\end{array}$ & $\begin{array}{c}\text { Sem } \\
\text { dispositivo }\end{array}$ & $\begin{array}{c}\text { Com } \\
\text { dispositivo }\end{array}$ & $\begin{array}{c}\text { Sem } \\
\text { dispositivo }\end{array}$ \\
\hline & 8 & 3 & 17 & 17 & 19 & 9 & 13 & 11 \\
\hline & $73 \%$ & $27 \%$ & $50 \%$ & $50 \%$ & $68 \%$ & $32 \%$ & $54 \%$ & $46 \%$ \\
\hline
\end{tabular}

Fonte: Rede Mapa/Coordenação no estado do Piauí (2018) 
Além da gestão democrática ser uma inovação na CF/88, é, também, inovação a repartição de competências constitucionais referentes à educação, implicando um modelo de federalismo de cooperação. Outra inovação é a figura do município como entidade política autônoma e, por esta razão, importa assinalar sua incumbência de estabelecer para o seu sistema de ensino normas de gestão democrática do ensino público consonante o disposto na CF/88 e na LDB/96 (NARDI, 2018).

O processo de municipalização do ensino é, por vezes, idealizado como o veículo de mudança de um modelo centralizador para um modelo firmado na perspectiva de mais participação e controle dos atores sociais da educação. Está o Piauí conseguindo andar no mesmo compasso dos ideais democráticos propostos na Carta de 1988, considerando que, dentre os 97 municípios com sistema, 40 não exprimem legalmente sobre a organização e funcionamento da gestão? Indo na direção do pensamento de Coutinho (2002, p. 12) - [...] "devemos ter muita cautela, hoje, quando usamos a palavra "democracia". [...] o fato de que todos hoje se digam "democratas" não significa que acreditem definitivamente na democracia" [...]. De igual modo podemos dizer que "não existe uma efetiva soberania popular e estamos longíssimos de termos assegurados os mínimos direitos econômicos, sociais e culturais para a maioria do povo" (BENEVIDES 2002, p. 73).

Assim, nossa indagação passa pela desconfiança de que a municipalização do ensino, mesmo no intuito de atender o disposto na $\mathrm{CF} / 88$, tem servido à reprodução das contradições sociais e da lógica do capital e do mercado, sendo que, na dinâmica das relações entre a sociedade e o sistema de ensino, merece uma análise se este tem se tornado um espaço de disputa à medida que nele pesam as concepções dominantes sobre a participação social e a democracia.

Sob o postulado do princípio da gestão democrática, identificamos nas leis analisadas, os restritamente expressos no art. 14 da LDB n. 9.394/96, em conformidade com os dados dispostos na tabela 3.

\section{Tabela 3. Frequência dos princípios da gestão democrática, expressos nas Leis, restritos ao art. 14 da LDB/96}

\begin{tabular}{|c|c|c|c|c|c|c|c|c|}
\hline \multirow{2}{*}{ 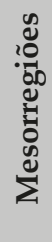 } & \multicolumn{2}{|c|}{$\begin{array}{c}\text { Norte Piauiense } \\
11 \text { Leis }\end{array}$} & \multicolumn{2}{|c|}{$\begin{array}{l}\text { Centro Norte } \\
\text { Piauiense } \\
\text { 34 Leis }\end{array}$} & \multicolumn{2}{|c|}{$\begin{array}{c}\text { Sudeste Piauiense } \\
28 \text { Leis }\end{array}$} & \multicolumn{2}{|c|}{$\begin{array}{c}\text { Sudoeste } \\
\text { Piauiense } \\
\text { 24 Leis }\end{array}$} \\
\hline & 2 & $18 \%$ & 9 & $26 \%$ & 6 & $21 \%$ & 3 & $12 \%$ \\
\hline
\end{tabular}

Fonte: Rede Mapa/Coordenação no estado do Piauí (2018) 
Os dados da tabela acima chamam à atenção no seguinte: i) 40 leis de institucionalização dos municípios piauienses traduzem o princípio da gestão democrática; ii) destas, 20 leis restringem-se ao Art. 14 da LDB/96. O artigo supra indica que os sistemas de ensino definirão as normas de gestão democrática, de acordo com as peculiaridades locais e conforme os seguintes princípios: I - participação dos profissionais da educação na elaboração do projeto pedagógico da escola; II - participação das comunidades escolar e local em conselhos escolares ou equivalentes.

Analisando os dados, identificamos certa superficialidade posta na legislação ao tratar o tema da gestão democrática do ensino público no contexto dos municípios piauienses. É forçoso concordar com Jacobi (2003, p. 317), quando relata que "são poucas as experiências de gestão municipal que assumem uma radicalidade democrática na gestão da coisa pública, assim como ampliam concretamente o potencial participativo", considerando, portanto, o entendimento do conceito de participação apresentado por Bordenave (1993), de que este, em seu sentido mais completo, implica fazer parte e tomar parte, interferindo nas decisões de forma crítica, consciente e responsável no próprio processo de participação. Entretanto, o que está em jogo é a necessidade de atualização dos princípios ético-políticos da democracia (JACOBI, 2003).

O principal desafio agora é o de construir uma ordem societária baseada na articulação da democracia com a participação social, representada uma maior permeabilidade da gestão às demandas dos sujeitos socais e políticos (JACOBI, 2003). Por esta lente, o conjunto da legislação analisada apresenta possibilidades de ampliação dos espaços e mecanismos de participação como forma de materializar o princípio constitucional da gestão democrática do ensino, como podemos identificar na tabela a seguir.

\section{Tabela 4. Frequência dos princípios da gestão democrática, expressos nas Leis, além dos expressos no art. 14 da LDB/96}

\begin{tabular}{|c|c|c|c|c|c|}
\hline \multirow[b]{2}{*}{ Princípios } & \multicolumn{4}{|c|}{ Mesorregiões } & TOTAL \\
\hline & $\begin{array}{l}\text { Norte } \\
11 \text { Leis }\end{array}$ & $\begin{array}{l}\text { Centro } \\
\text { Norte } \\
34 \text { Leis }\end{array}$ & $\begin{array}{l}\text { Sudeste } \\
28 \text { Leis }\end{array}$ & $\begin{array}{l}\text { Sudoeste } \\
24 \text { Leis }\end{array}$ & 97 Leis \\
\hline $\begin{array}{l}\text { Graus progressivos de } \\
\text { autonomia das escolas } \\
\text { na gestão pedagógica } \\
\text { administrativa e financeira }\end{array}$ & $\begin{array}{c}6 \\
54,5 \%\end{array}$ & $\begin{array}{c}3 \\
8,8 \%\end{array}$ & $\begin{array}{c}1 \\
3,6 \%\end{array}$ & - & $\begin{array}{c}10 \\
10,3 \%\end{array}$ \\
\hline $\begin{array}{l}\text { Liberdade de organização dos } \\
\text { segmentos da comunidade } \\
\text { escolar em associações, } \\
\text { grêmios. }\end{array}$ & $\begin{array}{c}6 \\
54,5 \%\end{array}$ & $\begin{array}{c}3 \\
8,8 \%\end{array}$ & $\begin{array}{c}1 \\
3,6 \%\end{array}$ & $\begin{array}{c}5 \\
20,8 \%\end{array}$ & $\begin{array}{c}15 \\
15,5 \%\end{array}$ \\
\hline
\end{tabular}




\begin{tabular}{|c|c|c|c|c|c|}
\hline \multirow[b]{2}{*}{ Princípios } & \multicolumn{4}{|c|}{ Mesorregiões } & \multirow{2}{*}{$\begin{array}{l}\text { TOTAL } \\
97 \text { Leis }\end{array}$} \\
\hline & $\begin{array}{l}\text { Norte } \\
11 \text { Leis }\end{array}$ & $\begin{array}{c}\text { Centro } \\
\text { Norte } \\
34 \text { Leis }\end{array}$ & $\begin{array}{l}\text { Sudeste } \\
28 \text { Leis }\end{array}$ & $\begin{array}{l}\text { Sudoeste } \\
24 \text { Leis }\end{array}$ & \\
\hline $\begin{array}{l}\text { Transparência dos } \\
\text { procedimentos administrativos, } \\
\text { pedagógicos e financeiros }\end{array}$ & $\begin{array}{c}6 \\
54,5 \%\end{array}$ & $\begin{array}{c}3 \\
8,8 \%\end{array}$ & $\begin{array}{c}1 \\
3,6 \%\end{array}$ & $\begin{array}{c}5 \\
20,8 \%\end{array}$ & $\begin{array}{c}15 \\
15,5 \%\end{array}$ \\
\hline $\begin{array}{l}\text { Descentralização das decisões } \\
\text { sobre o processo educacional }\end{array}$ & - & - & $\begin{array}{c}1 \\
3,6 \%\end{array}$ & $\begin{array}{c}5 \\
20,8 \%\end{array}$ & $\begin{array}{c}6 \\
6,9 \%\end{array}$ \\
\hline Eleição para o Conselho Escolar & - & $\begin{array}{c}5 \\
14,7 \%\end{array}$ & $\begin{array}{c}8 \\
28,6 \%\end{array}$ & $\begin{array}{c}3 \\
12,5 \%\end{array}$ & $\begin{array}{c}16 \\
16,5 \%\end{array}$ \\
\hline Eleição para a equipe diretiva & - & $\begin{array}{c}6 \\
17,6 \%\end{array}$ & $\begin{array}{c}8 \\
28,6 \%\end{array}$ & $\begin{array}{c}3 \\
12,5 \%\end{array}$ & $\begin{array}{c}17 \\
17,5 \%\end{array}$ \\
\hline $\begin{array}{l}\text { Autonomia da comunidade } \\
\text { escolar para definir o PPP }\end{array}$ & - & $\begin{array}{c}4 \\
11,7 \%\end{array}$ & - & $\begin{array}{c}3 \\
12,5 \%\end{array}$ & $\begin{array}{c}7 \\
7,2 \%\end{array}$ \\
\hline $\begin{array}{l}\text { Conferência Municipal de } \\
\text { Educação como fórum de } \\
\text { decisões }\end{array}$ & - & $\begin{array}{c}2 \\
5,8 \%\end{array}$ & $\begin{array}{c}11 \\
30,8 \%\end{array}$ & $\begin{array}{c}2 \\
8,3 \%\end{array}$ & $\begin{array}{c}15 \\
15,5 \%\end{array}$ \\
\hline Autonomia de gestão financeira & - & - & $\begin{array}{c}8 \\
28,6 \%\end{array}$ & - & $\begin{array}{c}8 \\
8,2 \%\end{array}$ \\
\hline
\end{tabular}

Fonte: Rede Mapa/Coordenação no estado do Piauí (2018)

Os dados nos permitem a seguinte análise: as formas de participação estão centradas na criação de novos espaços e mecanismos de articulação entre a comunidade, a escola e o sistema municipal de ensino, como, por exemplo: autonomia, liberdade, transparência, descentralização, eleição, Conferência Municipal de Educação como fórum máximo de deliberação coletiva. Dizemos, então, que estes princípios de participação identificados nas 97 Leis não atingem (isoladamente) a frequência de 20\%, mas, ainda assim, podemos afirmar que a gestão democrática como preceito constitucional não tem se limitado ao Art. 14 da LDB, pelo menos em parte, nos sistemas de ensino piauienses.

Até aqui, os dados desta pesquisa têm nos mostrado que o município, ao institucionalizar o sistema de ensino, está ao mesmo tempo fazendo certa opção de educação, como podemos, inclusive, constatar em outros estudos. Em pesquisas realizadas por Ribeiro; Iziquierdo; Santos (2012), os dados nos indicam que a capacidade de gestão democrática implica a competência das municipalidades de não apenas garantir a capacidade de descentralização, mas, também, a capacidade de participação, de transparência e materialização. Nardi; Rebelatto; Gamba (2013) reconhecem que a 
implementação de políticas e de organização do trabalho coletivo é um processo que ocorre sob determinada orientação política, consoante à dinâmica das relações que se desenvolvem em sociedade, logo, as opções político-institucionais dos municípios estão sob a égide de concepções políticas e ideológicas.

Ademais, a participação e a gestão democrática nos sistemas de ensino do Piauí é uma tarefa inconclusa, a exigir um projeto de democratização e de tomada de consciência nas relações humanas no interior dos próprios sistemas. Em outro estudo nesta direção, Lima; Aranda; Lima (2012) concluem que o significado do princípio da participação vem indicando que a democracia não tem conseguido se articular a uma concepção que legitime seus valores, e, empiricamente, argumentam que a participação ainda é reduzida, controlada e regulada.

Enfim, o número reduzido de sistemas municipais de ensino no Piauí pode ser explicado a partir de dificuldades da materialização da gestão por parte dos municípios, o que também não é caso específico deste estado. Podemos dizer isso, com base em pesquisa realizada em Santa Catarina, por Panis; Nardi (2014), quando chegam à conclusão de que as frágeis condições de sustentabilidade do regime de colaboração; a fragilidade financeira associada à falta de planejamento dos investimentos; a escassez de recursos humanos são variáveis que dificultam a institucionalização do princípio da gestão democrática do ensino em sistemas municipais. Assim posto, podemos dizer que a cultura da participação no estado do Piauí não tem andado no mesmo compasso do princípio da gestão democrática conferida pela $\mathrm{CF} / 88$, tendo em vista que 56,7\% dos municípios ainda dependem das deliberações do Sistema Estadual de Ensino por não terem instituído o sistema municipal de ensino.

\section{Considerações finais}

Orientados pela indagação sobre a posição do estado do Piauí - protagonista ou coadjuvante-em relação à autonomia dos sistemas municipais de ensino e a manifestação em cumprir o preceito constitucional da gestão democrática, nos orientamos pelo estudo teórico sobre a dinâmica do princípio desse modelo de gestão e, também, pelo estudo empírico de análise documental das orientações legais contidas no conjunto da legislação municipal a fim de compreender o lugar da gestão democrática do ensino público.

Considerando o estudo realizado, foi possível chegar a algumas conclusões: a partir da CF/88 foi incumbido aos municípios a organização de seus próprios sistemas de ensino e, em consequência, os princípios da gestão democrática do ensino público; em atendimento à CF e a LDB, os municípios piauienses são orientados pelo Conselho Estadual de Educação no processo de institucionalização do ensino em âmbito municipal; os municípios autônomos tendem a realçar a autonomia nas decisões pedagógicas, 
administrativas e financeiras na educação. Reconhecemos ser possível que no modelo de gestão democrática o sistema municipal de ensino se disponha a romper com o caráter patrimonial na prática governamental, conforme resultados de pesquisa realizada por Pereira (2012).

Ao nosso ver, o Piauí assume, considerando o atual quadro de municipalização do ensino público, uma posição de coadjuvante quanto à institucionalização do princípio da gestão democrática, conferida na CF/88. Ainda assim, longe de esgotar a discussão, os resultados permitem confirmar que os desafios e as possibilidades em relação à gestão democrática no âmbito municipal seguem presentes, renovando-se e redirecionando-se à luz dos avanços conquistados e da melhor compreensão das condições concretas que a favorecem ou obstaculizam.

Recebido: 15/09/2018 e Aceito: 02/12/2018

\section{Referências}

BARDIN, Laurence. Análise de conteúdo. Lisboa: 70-LDA, 2010.

BENEVIDES, Maria Victoria. A construção da democracia no Brasil pós-ditadura militar. In: FÁVERO, Osmar; SEMERARO, Giovanni (Org.). Democracia e construção do público no pensamento educacional brasileiro. Petrópolis-RJ: Vozes, 2002, p. 69-86.

BORDENAVE, Juan E. Díaz. O que é participação. São Paulo: Brasiliense, 1983.

BRASIL. Constituição da República Federativa do Brasil, 1988. Brasília, DF, 1988. Disponível em: http://www.planalto.gov.br/ccivil_03/constituicao/constituicao.htm. Acesso em 30 de junho de 2018.

. Lei no. 9.394, de 20 de dezembro de 1996. Estabelece as diretrizes e bases da educação nacional. Diário Oficial [da] República Federativa do Brasil, Poder Executivo, Brasília, DF, 21 dez. 1996. Seção 1, p. 27833-27841.

COUTINHO, Carlos Nelson. A democracia na batalha das ideias e nas lutas políticas do Brasil de hoje. In: FÁVERO, Osmar; SEMERARO, Giovanni (Org.). Democracia e construção do público no pensamento educacional brasileiro. Petrópolis-RJ: Vozes, 2002, p.11-40.

JACOBI, Pedro Roberto. Espaços públicos e práticas participativas na gestão do meio ambiente no Brasil. Sociedade e Estado, UnB, Brasília, v. 18, n. 1/2, p. 137-154, jan./dez. 2003.

LIMA, Antônio Bosco de. Estado, educação e controle social: introduzindo tema. Revista Brasileira de Política e Administração da Educação, Porto Alegre, Anpae, v. 25, n. 3, set-dez, p. 473-488, 2009.

LIMA, Paulo Gomes; ARANDA, Maria Alice de Miranda; LIMA, Antônio Bosco de. Políticas educacionais, participação e gestão democrática da escola na contemporaneidade brasileira. Rev. Ensaio Pesquisa em Educação em Ciências. Belo Horizonte, UFMG, v. 14, n. 01, p. 51-64, jan./abr, 2012. 
IBGE. Senso demográfico 2010: retratos do Brasil e do Piauí. Teresina, 12 de agosto de 2011. Disponível em https://www.google.com.br/search?q=mapa+com+mesorregi\%C3\%B5es+geogr\%C3\%. Acesso em 29 de agosto de 2018.

NARDI, Elton Luiz. Gestão democrática do ensino público na educação básica: dimensões comuns e arranjos institucionais sinalizados em bases normativas de sistemas municipais de ensino. Educar em Revista, Curitiba, UFPR, v. 34, n. 68, p. 123-136, mar./abr. 2018.

NARDI, Elton; REBELATTO, Durlei Maria Bernardon; GAMBA, Ivan Carlos. Opções políticoinstitucionais de sistemas municipais de ensino: para onde caminha a gestão democrática do ensino público? Roteiro, Joaçaba, Unoesc, v. 38, n. 1, p. 169-194, jan.jjun. 2013.

PANIS, Ledriana Minusculi; NARDI, Elton, Luiz Nardi. Implementação de sistemas de ensino: entre condições locais e expectativas de desenvolvimento educacional. Educação: Teoria e Prática, Rio Claro, Unesp, v. 24, n.47, p. 156-175, set./dez. 2014.

PEREIRA, Maria do Socorro Vasconcelos. A institucionalização dos sistemas municipais de ensino na realidade paraense: obstáculos e possibilidades: o caso do Município de Barcarena. Dissertação (Mestrado em Educação). Universidade Federal do Pará, Instituto de Ciências da Educação, Programa de Pós-Graduação em Educação. Belém, 2012.

PEREIRA, Sueli Menezes. Organização e funcionamento do sistema municipal de ensino: entre o legal e o real. Políticas Educativas, Porto Alegre, UFRGS, v. 8, n. 1, p. 34-50, 2014.

PIAUÍ. Lei no 5.101 de 23 de novembro de 1999. Dispõe sobre o sistema de ensino do Estado e dá outras providências. Disponível em: http://servleg.al.pi.gov.br:9080/ALEPI/sapl_documentos/norma_ juridica/1812_texto_integral. Acesso em 10 de março de 2016.

. Parecer CEE/PI no 054, de 03 de dezembro de 2004. Orienta os municípios do Piauí sobre a organização de seus Sistemas de Ensino e dá outras providências. Teresina: Conselho Estadual de Educação, 2004.

REDE MAPA. Frequência dos municípios piauienses com e sem sistema próprio de ensino público. Banco de dados da Coordenação do Piauí/Universidade Estadual do Piauí, 2016.

Banco de dados. Coordenação do Piauí/Universidade Estadual do Piauí, 2018.

RIBEIRO, Elizabete Matos; IZIQUIERDO, Oscar Chassagnes; SANTOS, Rginaldo Souza. Avaliação da capacidade de gestão democrática em municípios baianos. Organização \& Sociedade, Salvador, UFBA, v.19 - n.63, out/dez/2012, p. 717-736. Disponível em www.revistaoes.ufba.br. Acesso em 20 de agosto de 2018.

SARMENTO, Diva Chaves. Criação dos sistemas municipais de ensino. Educ. Soc., Campinas, CEDES, vol. 26, n. 93, p. 1363-1390, Set./Dez. 2005.

SOUZA, Donaldo Bello de; FARIA, Lia Ciomar Macedo de. Reforma do Estado, descentralização e municipalização do ensino no Brasil: a gestão política dos sistemas públicos de ensino pós-LDB 9394/96. Ensaio: Avaliação Políticas Públicas Educacionais, Cesgranrio, Rio de Janeiro, v.12, n.45, p. 925-944, out./dez. 2004.

WERLE, F. O. C.; THUM, A. B.; ANDRADE, A. C. Processo nacional de avaliação o rendimento escolar: tema esquecido entre os sistemas municipais de ensino. Ensaio: Avaliação e Políticas Públicas em Educação, Cesgranrio, Rio de Janeiro, v. 17, n. 64, p. 397-420, jul./set. 2009. 